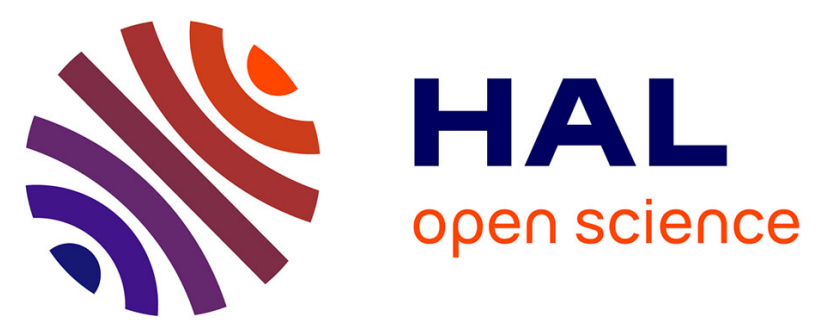

\title{
Non-invasive, in vivo monitoring of neuronal transport impairment in a mouse model of tauopathy using MEMRI
}

\author{
Anne Bertrand, Umer Khan, Dung M. Hoang, Dmitry S. Novikov, Pavan
} Krishnamurthy, Hameetha B. Rajamohamed Sait, Benjamin W. Little, Einar

M. Sigurdsson, Youssef Z. Wadghiri

\section{To cite this version:}

Anne Bertrand, Umer Khan, Dung M. Hoang, Dmitry S. Novikov, Pavan Krishnamurthy, et al.. Noninvasive, in vivo monitoring of neuronal transport impairment in a mouse model of tauopathy using MEMRI. NeuroImage, 2013, 64, pp.693 - 702. 10.1016/j.neuroimage.2012.08.065 . hal-01439335

\section{HAL Id: hal-01439335 https://hal.inria.fr/hal-01439335}

Submitted on 18 Jan 2017

HAL is a multi-disciplinary open access archive for the deposit and dissemination of scientific research documents, whether they are published or not. The documents may come from teaching and research institutions in France or abroad, or from public or private research centers.
L'archive ouverte pluridisciplinaire HAL, est destinée au dépôt et à la diffusion de documents scientifiques de niveau recherche, publiés ou non, émanant des établissements d'enseignement et de recherche français ou étrangers, des laboratoires publics ou privés. 


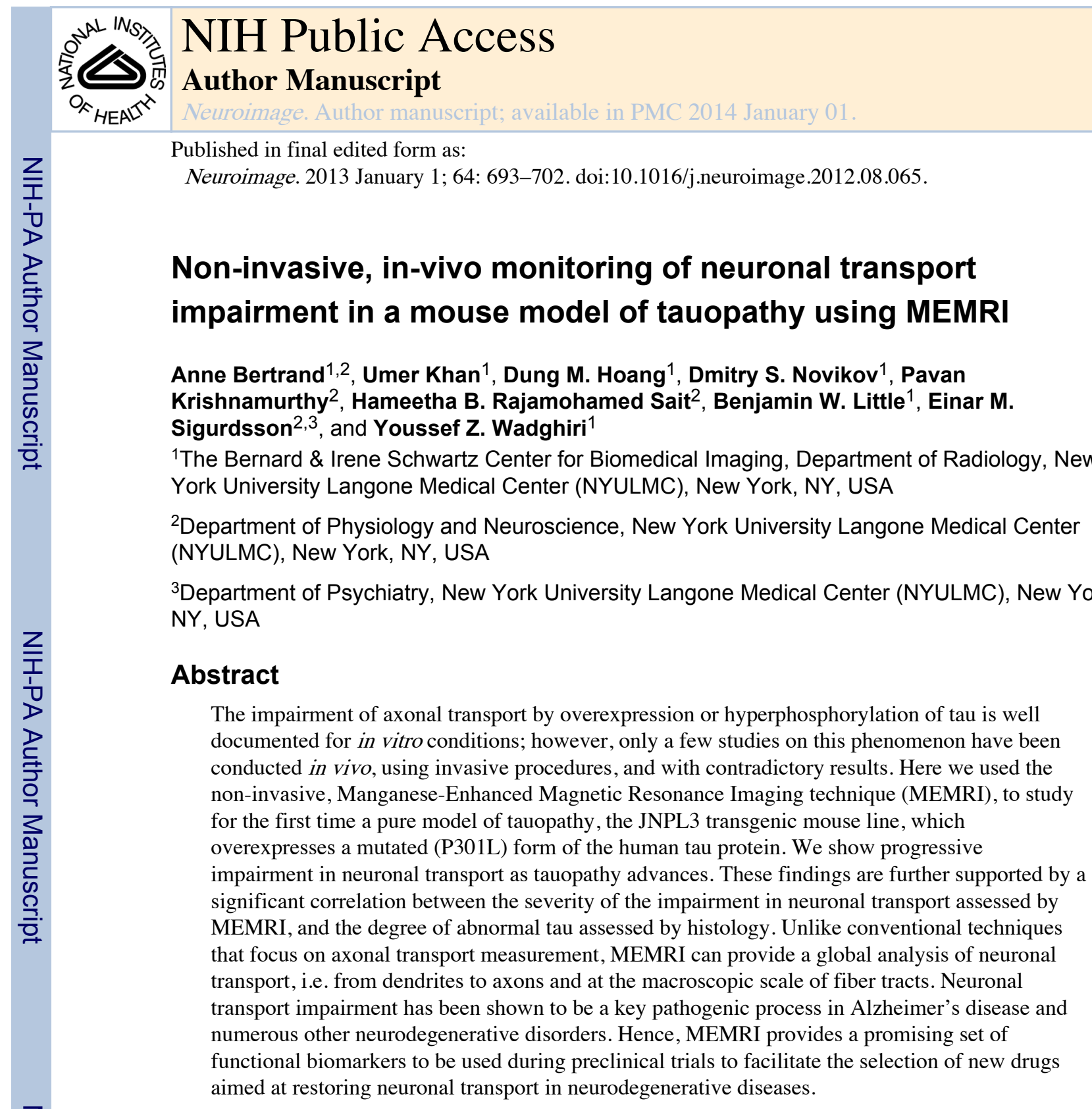

\section{Keywords}

Alzheimer's disease; MEMRI; Axonal transport; Neuronal transport; Tauopathy

\footnotetext{
(C) 2012 Elsevier Inc. All rights reserved.

Corresponding authors: Youssef Z. Wadghiri, NYULMC, The Bernard \& Irene Schwartz Center for Biomedical Imaging, Department of Radiology, 660 First Ave 4th Floor Room 444, New York, NY 10016, Tel: 001 (212) 263-3336, Fax: 001 (212) 263-7541, wadghiri@med.nyu.edu Or Einar M. Sigurdsson, NYULMC, Department of Physiology and Neuroscience, 550 First Ave, Medical Science Building, Room MSB459, New York, NY 10016, Tel: 001 (212) 263-3913, Fax: 001 (212) 263-2160, einar.sigurdsson@nyumc.org.

Publisher's Disclaimer: This is a PDF file of an unedited manuscript that has been accepted for publication. As a service to our customers we are providing this early version of the manuscript. The manuscript will undergo copyediting, typesetting, and review of the resulting proof before it is published in its final citable form. Please note that during the production process errors may be discovered which could affect the content, and all legal disclaimers that apply to the journal pertain.
} 


\section{Introduction}

Tauopathies are neurodegenerative diseases defined by the pathological accumulation of filamentous tau in the central nervous system. Tau is a microtubule-associated protein predominantly expressed in the axonal compartment of neurons, where it promotes microtubule assembly and stabilization. Among tauopathies, the most frequent by far is Alzheimer's disease, followed by progressive supranuclear palsy, corticobasal degeneration and Pick's disease.

In these tauopathies, tau becomes abnormally phosphorylated, accumulates in the somatodendritic compartment of neurons and aggregates into neurofibrillary tangles The in vitro evidence that abnormally phosphorylated tau is less able to stabilize microtubules (Bramblett et al., 1993; Drechsel et al., 1992; Grundke-Iqbal et al., 1986; Iqbal et al., 1986) led to the formulation of the "tau-microtubule" hypothesis, which states that tau phosphorylation provokes microtubule breakdown, causing axonal transport impairment and subsequent synaptic dysfunction (Iqbal and Grundke-Iqbal, 1991; Lee and Trojanowski, 1992). Studies in cellular models (Dayanandan et al., 1999; Lovestone et al., 1996) and in a drosophila model of tauopathy (Cowan et al., 2010; Mudher et al., 2004) have confirmed that tau phosphorylation can induce microtubule breakdown. An alternative hypothesis states that the overexpression of normal, non-phosphorylated tau can impair axonal trafficking by stearic hindrance of motors proteins, as shown in vitro (Dixit et al., 2008; Seitz et al., 2002; Vershinin et al., 2007) and in cells (Ebneth et al., 1998; LaPointe et al., 2009; Mandelkow et al., 2003; Stoothoff et al., 2009; Trinczek et al., 1999); tau phosphorylation being considered as a compensatory mechanism which aims at rescuing axonal transport (Falzone et al., 2010; Falzone et al., 2009; Vossel et al., 2010). Regardless of the exact mechanism, both normal and hyperphosphorylated tau can aggregate and thereby impair axonal transport during the course of the disease. Importantly, axonopathy and transport deficits appear to occur early in the pathogenesis of AD and related mouse models (Stokin et al., 2005).

These effects of pathological tau on axonal transport, as mentioned above, are described at the microscopic scale of individual axons either ex vivo or in vitro and using cell culture and drosophila model system. However, they may not be relevant at the macroscopic scale of fiber tracts. The complexity of neuronal networks, and the various interactions that exist between glial and neuronal cells, make one cautious when interpreting the results of singleaxon studies and inferring their relevance to the mammalian brain. Hence, the effects of tauopathy on axonal transport need to be assessed at the macroscopic level using mammalian models. Only a few axonal transport studies have been conducted in mouse models of tauopathy, and their results have been contradictory. Two studies performed in transgenic mice expressing normal human tau showed either retarded (Ishihara et al., 1999) or normal axonal transport (Yuan et al., 2008). Two additional reports using transgenic mice expressing mutant human tau found some evidence of impairment in axonal transport (Ittner et al., 2008; Zhang et al., 2004), although one of those was limited to the transport of tau itself, and not organelles and cargo proteins (Zhang et al., 2004). None of these studies established a quantitative correlation between the level of abnormal tau and the degree of axonal impairment. Indeed, there is still a need to prove in vivo that axonal transport deficits represent a significant event during the course of tauopathy.

The reason for the contradictory findings to date on axonal transport in mouse models of tauopathy may be related to the models employed, but also to the technical challenges of measuring axonal transport. These prior studies in mouse models required invasive techniques, such as a nerve ligation or injection into the spinal cord. Nerve ligation induces nerve injury and local ischemia, which may interfere with normal axonal transport (Ittner et 
al., 2008; Zhang et al., 2004). Injection of radiolabelled amino acids requires deep surgical procedures which can also induce ischemic-hemorrhagic changes in the area of interest (Zhang et al., 2004; Zhang et al., 2005). Both these techniques rely on a post-mortem quantification of the transported cargoes, and thus can only evaluate transport mechanisms at a single time point for each animal. Lastly and importantly, these transport measurements have always been done in the axonal compartment, as it is technically easier to access than the dendritic trees. However, it is well known that pathological tau accumulation takes place in the somato-dendritic compartment of neurons (Lee et al., 2001). Hence, the ideal approach for the study of active transport in mouse models of tauopathy would provide a non-invasive, longitudinal quantification of transport in all neuronal compartments (i.e. soma, dendrites and axons), thus giving a comprehensive, 4D picture of neuronal transport in fiber tracts.

Manganese-Enhanced MRI (MEMRI) is a non-invasive imaging technique based on the physicochemical properties of manganese. As a calcium-analogue, manganese enters neurons via $\mathrm{Ca}^{2+}$ channels (Drapeau and Nachshen, 1984; Lu et al., 2007; Narita et al., 1990; Sloot and Gramsbergen, 1994), is transported along the microtubule system by active transport partially dependent on kinesin (Bearer et al., 2007a; Sloot and Gramsbergen, 1994; Smith et al., 2007; Takeda et al., 1998b), is released at the synaptic cleft (Takeda et al., 1998b), and is taken up by the post-synaptic neuron (Saleem et al., 2002; Takeda et al., 1998a; Tjalve et al., 1996; Tjalve et al., 1995). Thanks to its paramagnetic properties, manganese causes a local increase of MR signal intensity in neurons that can be detected on T1-weighted images (Lin and Koretsky, 1997). Hence, by repeated MR examinations over time, the displacement of manganese in neurons can be dynamically monitored (Pautler and Koretsky, 2002; Pautler et al., 1998). For these reasons, MEMRI can be used as a noninvasive in vivo tool to study neuronal transport in animal models, either in the visual system using intraocular injection of manganese (Bearer et al., 2007a), in the olfactory system using intranasal delivery of manganese (Cross et al., 2008; Smith et al., 2007), in deep fiber systems using intracerebral injection of manganese (Bearer et al., 2007b), or in peripheral nerves following topical injection of manganese. (Matsuda et al., 2010). MEMRI studies of the olfactory system have reported an in vivo impairment of axonal transport in transgenic mouse model of amyloid $\beta$ deposition (Massaad et al.; Smith et al., 2007; Smith et al., 2010a) and in a triple transgenic mouse model with both amyloid $\beta$ deposition and neurofibrillary tangles (Kim et al., 2011). One MEMRI study of the olfactory system focusing on the interaction between APP and tau included a subgroup of animals expressing human mutated tau. Results from this subgroup suggested an in vivo impairment of axonal transport related to tauopathy. However this study did not comprise any assessment of pathological tau in the brain of the animals (Smith et al., 2010b).

Our goal was to examine by MEMRI a mouse model of tauopathy to address the following questions:

- Can we detect in vivo an effect of mutant human tau on neuronal transport?

- Can we correlate these alterations of neuronal transport with the degree of tauopathy, thus providing a functional biomarker of pathological tau in mice?

\section{Material and Methods}

\subsection{Animals}

Imaging experiments were performed on homozygous JNPL3 transgenic mice (Taconic; (Lewis et al., 2000)) and wild-type (WT) control mice of the same strain background. (C57BL/6, DBA/2 and SW mixed background). In this homozygous model, tau pathology becomes evident around 2-3 months of age and is severe at 9 months (Asuni et al., 2007). 25 
animals (13 Tg and 12 WT) were imaged and monitored longitudinally at 3,6 and 9 months of age. To examine if there was a correlation between the extent of tauopathy and changes in axonal transport, mice were euthanized and sacrificed at each of the selected time points: 8 animals (4 Tg and 4 WT) after the 3-month old examination, 10 animals (5 Tg and 5 WT) after the 6-month old examination, and 7 animals (4 Tg and 3 WT) after the 9-month old examination. In addition, to control for possible confounding effects related to the potentially cumulative neurotoxicity of manganese, a supplementary group of 10 mice $(5 \mathrm{Tg}$ and 5 WT) was examined at 9 months only and then euthanized. Each group of mice included comparable number of males and females. A total of 35 animals were used for the study. Procedures were performed in accordance with the Institutional Animal Care and Use Committee at the New York University School of Medicine.

\section{2. $\mathrm{MnCl}_{2}$ administration and $\mathrm{MR}$ scanning}

$\mathrm{MnCl}_{2}\left(1.5 \mu \mathrm{L}\right.$ of $\left.5 \mathrm{M} \mathrm{MnCl}_{2}\right)$ was administered under anesthesia (5\% isoflurane) into one nostril of the mouse using a micropipette under microscopic control. Mice were maintained under anesthesia for 1 minute after the Mn administration, in order to delay the cough reflex and to ensure a correct penetration of $\mathrm{Mn}$ in the nasal epithelium. Still, cough reflex did occur in most of the animals after the anesthesia, and may have caused some variation in the exact volume of manganese delivered; however, these random variations were equally likely to occur in both WT and Tg animals. After the instillation, each mouse was allowed to recover for a few minutes on a heating pad, and was then transferred to its cage.

During each imaging time course set, mice were scanned 9 times: once before manganese injection, 7 times during the 2 days following the injection (at 1, 4, 8, 12, 24, 36 and $48 \mathrm{~h}$ after injection), and finally 7-10 days after the injection. MRI scans were performed on a 7T micro-MRI system, consisting of a 200-mm horizontal bore magnet (Magnex Scientific, UK) with an actively shielded gradient coil insert (Bruker BGA-9S; ID 90-mm, 750-mT/m gradient strength, $100-\mu$ s rise time). The same in-house birdcage quadrature coil was used for all image acquisitions (ID=22mm, length $29 \mathrm{~mm}$ ). Each scan consisted of a 3D T1-SPGR sequence with the following parameters: FOV $=19.2 \times 19.2 \times 9.6 \mathrm{~mm}$, matrix size $=128 \times$ $128 \times 64$, spatial resolution $=(150 \mu \mathrm{m})^{3}, \mathrm{TR} / \mathrm{TE}=15 / 4 \mathrm{~ms}$, averages $=6$, acquisition time $=$ $15 \mathrm{~min}$. Flip angle $\left(18^{\circ}\right)$ was chosen to provide the greatest T1-enhancement contrast (Neelavalli and Haacke, 2007). Ten minutes before MR imaging, each mouse was anesthetized with 5\% isoflurane, and then placed in an in-house holder system including a tooth bar, in order to maintain the head in a reproducible and stationary position in the coil. During MR imaging, each mouse was kept under anesthesia using isoflurane in air (1-2\%), its body temperature being maintained at $35-37^{\circ} \mathrm{C}$ with a heated waterbed, and its respiratory rate being constantly monitored. The level of isoflurane was continuously adjusted so that the respiratory rate was always between 40 and 60 per minute. After MR imaging, each mouse was allowed to recover on a heating pad for a few minutes, and was then transferred back to its cage until the next scan. The total time under anesthesia for each mouse did not exceed 30 min per scan.

\subsection{MR image processing}

All the MR datasets were processed using the ImageJ software (NIH, Rockville, MD). A rigid registration was systematically performed between the MRI datasets acquired serially from each individual mouse at 9 different time points using an automatic registration with the Rigid_Registration.jar plugin (J Schindelin, M Longair). Unlike inter-subject registration, the intra-subject realignment assessed for the 9 set of image time points proved effective since it is less prone to anatomical mis-registration minimizing translation requirement. Four regions of interest (ROI) were defined on the following structures using a mouse brain atlas: the glomerular layer, the mitral cell layer, the anterior part of the piriform 
cortex, and the pons; the latter was used to normalize signal intensities at each time point (see supplementary Fig.8).

The contralateral side was not used for normalization as some degree of enhancement was observed in about half of the animals in similar proportion in both Tg and WT groups. For each mouse, the normalized signal intensities in each ROI were plotted and fitted to a previously described tract-tracing bolus model (Cross et al., 2008) using an in-house Matlab fitting routine (The Mathworks 2009). Briefly, the manganese transport was assumed to follow a drift/diffusion model described by the one-dimensional Fokker-Planck equation. The parameters defining the time-intensity curves acquired experimentally were extracted using a nonlinear least square fitting based on the Levenberg Marquardt algorithm. For each mouse, the parameter of global scaling, reflective of the initial neuronal uptake of manganese, was estimated by fitting in only the glomerular layer ROI, which was the closest ROI to the site of infusion; the same value was subsequently used in the two downstream ROI (mitral cell layer and anterior piriform cortex). The fitting process allowed us to determine the curve profile of normalized signal intensity changes in each ROI as a function of time, which reflects the local variations in manganese concentration over time (Wood and Hardy, 1993). From the fitted curves, we extracted the following parameters: value of the peak of intensity $(\mathrm{Pv})$, time-to-peak of intensity $(\mathrm{Pt})$, and maximal value of the ascending slope (Sv).

\subsection{Histology}

These procedures were performed as previously described in detail (Sigurdsson, 2005).

Briefly, following MR examinations, the animals were terminally anesthetized with ketamine and xylazine ( $300 \mathrm{mg} / \mathrm{kg}$ Ketamine $+60 \mathrm{mg} / \mathrm{kg}$ Xylazine i.p.) and perfused transaortically with phosphate buffered saline. The right half of the brains, including right olfactory bulbs, were used for this study and were immersion fixed overnight in $2 \%$ periodate-lysine-paraformaldehyde solution (PLP), and subsequently placed in $2 \% \mathrm{DMSO} /$ $20 \%$ glycerol in phosphate-buffered saline (PBS) overnight or until sectioned. Serial coronal sections $(40 \mu \mathrm{m})$ were cut in a cryostat, and four series of every tenth section were used for staining. Sections were stored at $-30^{\circ} \mathrm{C}$ in an ethylene glycol cryoprotectant until used for histology.

Immunohistochemistry was performed as previously described (Sigurdsson, 2005). Briefly, following several washes in PBS, free-floating sections were incubated in $0.3 \% \mathrm{H}_{2} \mathrm{O}_{2}$ for 15 min to block endogenous peroxidase activity, and then placed in a blocking solution for $1 \mathrm{~h}$ at room temperature, to block nonspecific binding. The blocking solution consisted of: 1) $5 \%$ milk in TBS (PHF1); 2) A mouse-on-mouse (MOM) blocking reagent from the MOM immunodetection kit (Vector Laboratories, Burlingame, CA; MC1); 3) A polyclonal antibody diluent solution with $2 \%$ bovine serum albumin and $10 \%$ goat serum (GFAP). The sections were then incubated overnight in the primary antibodies (see below Antibodies for immunohistochemistry). The biotinylated IgG secondary antibody and the avidin and peroxidase solutions (anti-mouse or anti-rabbit antibody, Vector Laboratories, Elite Kits, Burlingame, CA) were used at a 1:1000 dilution. Antibody staining was revealed with 3,3'diaminobenzidine tetrahydrochloride (Sigma) with nickel ammonium sulfate (Mallinckrodt, Paris, KY) intensification. The sections were then mounted onto slides, air-dried, dehydrated and defatted, cleared in CitriSolv (Fisher Scientific), and cover slipped with Depex mounting media.

For neuronal counting, sections were stained with cresyl violet. Sections were first mounted onto slides, air-dried, defatted, progressively rehydrated and stained for 75 seconds in a solution of $0.1 \%$ cresyl violet (Sigma) in $0.01 \mathrm{M}$ acetic acid, then dehydrated, cleared in CitriSolv (Fisher Scientific), and cover slipped with Depex mounting media. 


\subsection{Antibodies for immunohistochemistry}

PHF1 and MC1 monoclonal antibodies (kindly provided by Dr. Peter Davies) were used at 1:2500 (PHF1) or 1:50 (MC1) dilution. PHF1 IgG1 antibody recognizes phosphorylated serine 396 and 404 located outside the microtubule-binding repeat on the $\mathrm{C}$ terminal of the tau protein (Otvos et al., 1994). MC1 antibody is a conformation dependent IgG1 antibody that is similar to Alz-50 (IgM). Its reactivity depends on both the $\mathrm{N}$ terminus (amino acids 7-9), and an amino acid sequence of tau (amino acids 313-322) in the third microtubule binding domain that is both necessary and sufficient for in vitro formation of filamentous aggregates of tau similar to those seen in $\mathrm{AD}$. However the pathological conformation of tau recognized by $\mathrm{MC1}$ seems to precede the aggregation of tau into filaments and the resultant neurofibrillary degeneration (Jicha et al., 1999). Both antibodies recognize tau pathology in the JNPL3 mouse model (Lewis et al., 2000). GFAP polyclonal antibody (Dako, Glostrup, Denmark) was used at 1:1000. GFAP antibody recognizes the glial fibrillary acidic protein, a $50 \mathrm{kDa}$ intracytoplasmic filamentous protein that constitutes a portion of the cytoskeleton in astrocytes, and has been shown to be the most specific marker for cells of astrocytic origin (Eng et al., 2000)

\subsection{Quantification of $M C 1, P H F 1$ and GFAP staining}

In order to correlate MEMRI parameters with the expression of mutant human tau, we quantified the level of staining in 3 areas (Fig1): 1) The mitral cell layer, which corresponds to our second ROI on MR images and contains the cell bodies of mitral cells; 2) The external plexiform layer, which is located just upstream of the mitral cell layer and contains the dendritic processes of mitral cells, and 3) The anterior piriform cortex, which corresponds to our third ROI on MR images, and contains cell bodies and axonal/dendritic processes of cortical neurons. In the glomerular layer, which was our first ROI on MR images, the degree of staining was not accurately quantifiable because of high level of nonspecific staining at the edges of the olfactory bulb.

Quantitative analysis of tissue sections was performed using the ImageJ software (NIH, Rockville, MD). Six sections were analyzed per animal and per antibody stain (PHF1, MC1, GFAP), every 2 sections corresponding to each ROI (external plexiform layer, mitral cell layer, anterior piriform cortex). After digitization, sections were analyzed based on the same rectangular ROI manually placed within the layer of interest. A segmentation threshold was visually established to accurately identify staining in these areas. The measurement consisted of the fractional stained area in each ROI at 200X magnification (20X objective).

\subsection{Cell counting}

Cell counting was first performed in all ROI using a semi-quantitative method, by a visual ranking of cell density on a score of 1 to 4 . Subsequently, unbiased neuronal counting was performed in the mitral cell layer of all animals. The mitral cell layer was chosen because of its easy delineation on coronal sections, which allows for cell counting in the whole layer. We used stereological image analysis software (StereoInvestigator 10, MicroBrightField Bioscience, Williston, VT) controlling a Ludl motorized stage in a Leica DM5000B microscope. The edges of the mitral cell layer were traced at low power (200 magnification, $20 \mathrm{X}$ objective) and counting frames of $225 \mu \mathrm{m}^{2}$ were selected at random on a sampling grid by the image analysis software. Twelve to twenty counting frames were used on each section, representing $5 \%$ of the total area of the mitral cell layer visible on the corresponding section. Neurons were counted through a $100 \mathrm{X}$ objective with the optical fractionator method. Three to four sections per animal were analyzed. Final estimated cell counts in the mitral cell layer were expressed as number of neurons per $\mathrm{mm}^{3}$. 


\subsection{Statistical analysis}

All the data were analyzed with GraphPad (San Diego, CA) Prism 5.0. Functional parameters of manganese propagation extracted from fitted MRI data (Pv, Pt, Sv), immunoreactivity on brain sections and cell density in the mitral cell layer were compared by two-tailed $t$ test, either unpaired (comparing WT and Tg at the same age) or paired (comparing same animals at 3 and 6 months of age), except when the data failed at least two of the three normality tests (D'Agostino and Pearson, Shapiro-Wilk and KolmogorovSmirnov normality tests) or the F test to compare variances. In these cases data were compared using Mann-Whitney test (comparing WT and Tg at the at the same age) or the Kruskall-Wallis test (comparing same animals at 3 and 6 months of age). Correlations between functional parameters of manganese propagation and tau pathology were assessed by Pearson correlation coefficient, except when the data failed at least two of the three normality tests or the test of equal variances, in these cases correlations were assessed using the non parametric Spearman correlation coefficient. Due to typical variations in the degree of tau pathology observed in this mouse model between age-matched $\mathrm{Tg}$ animals, we considered only the 17 animals that were imaged both at 3 and 6 months of age for the analysis of the functional parameters defining the manganese propagation ( $\mathrm{Pv}, \mathrm{Pt}, \mathrm{Sv})$,

\section{Results}

\subsection{MEMRI detects an age-related impairment of manganese propagation in the olfactory system of JNPL3 tauopathy mice}

Curve profiles of normalized signal intensities, reflective of manganese propagation, were similar between WT and Tg at 3 months of age, but showed marked differences at 6 months of age, for both the glomerular layer (Fig. 2, A\&B) and the mitral cell layer (Fig. 3, A\&B). The fitting process performed in each mouse allowed us to analyze 3 parameters: the value of the peak of signal intensity $(\mathrm{Pv})$, the time-to-peak of signal intensity $(\mathrm{Pt})$, and the maximal value of the ascending slope of signal intensity (Sv) (Fig.2\&3 C-E). In our first ROI, the glomerular layer, all 3 parameters were significantly altered in Tg animals between 3 and 6 months of age: Pv was decreased, Sv was decreased and Pt was delayed (Fig.2 C-E). In our second ROI, the mitral cell layer, curve profiles were globally lower than in the glomerular layer, but the same significant phenomena was observed (Fig $3 \mathrm{C}-\mathrm{E}$ ). In our third ROI, the piriform cortex, curve profiles were even lower, and significant differences were not obtained neither when comparing age, nor when comparing Tg vs. WT mice (data not shown).

\subsection{Manganese transport dynamics, reflective of neuronal transport, correlates with the degree of tau pathology in the olfactory system of JNPL3 tauopathy mice}

We compared the observed modifications in MEMRI parameters ( $\mathrm{Pv}, \mathrm{Pt}$ and $\mathrm{Sv}$ ) with the degree of tau pathology in the corresponding neurons. Tau pathology could not be reliably quantified in the glomerular layer because of high levels of non-specific staining within this region; thus, we focused for this analysis on the mitral cells. The degree of staining was assessed in the external plexiform layer, which corresponds to the dendritic compartment of mitral cells, and in the "mitral cell layer" proper, which corresponds to the somatic compartment of mitral cells (Fig.4, and supplementary Fig. 9 A-H). In both compartments, MC1 and PHF1 immunoreactivity (IR) were higher in the Tg animals than in WT controls. PHF1 IR did not differ as robustly as MC1 IR, likely because of a moderate PHF1 IR in WT animals (Fig 4 B\&D, p<0.05).

The peak of signal intensity (Pv) was the MEMRI parameter that demonstrated the strongest correlation with the degree of tauopathy (Fig.5 A-D). Pv correlated significantly with the level of somatic PHF1 and MC1 IR (Fig.5A\&B, r=-0.38, p < 0.05 and r=-0.46, p $<0.01$ 
respectively), and even more strongly with the level of dendritic PHF1 and MC1 IR (Fig. $5 C \& D, r=-0.5, p<0.005$ for both). A threshold of 1.85 for the peak value allowed the separation of all Tg animals with MC1-positive dendrites (stained area $>0.5 \%$ ), from all $\mathrm{Tg}$ animals with low levels of MC1 dendritic staining (stained area $<0.1 \%$ ) and all except one WT animal (Fig. 5.D). When considering only the group of $\mathrm{Tg}$ animals, correlations were not significant between Pv and somatic PHF1 staining, dendritic PHF1 staining or somatic $\mathrm{MC1}$ staining, but was highly significant between $\mathrm{Pv}$ and dendritic MC1 staining ( $\mathrm{r}=-0.78$, $\mathrm{p}=0.0002)$.

Among the two other parameters ( $\mathrm{Sv}$ and $\mathrm{Pt}$ ), only $\mathrm{Sv}$ showed a significant correlation with the level of somatic and dendritic MC1 IR ( $r=-0.44, \mathrm{p}<0.01$ and $\mathrm{r}=-0.45, \mathrm{p}<0.01$ respectively). The correlation of $\mathrm{Sv}$ with dendritic MC1 IR remained significant when considering the group of $\mathrm{Tg}$ animals only $(\mathrm{r}=-0.50, \mathrm{p}<0.05$, data not shown).

\subsection{WT and Tg JNPL3 tauopathy mice did not differ in the number of glial cells and neurons in the olfactory system, further supporting that the observed differences in Mn dynamics are caused by perturbations in neuronal transport}

It is well-known that in addition to its transport in neurons, manganese can also be stored in astrocytes (Aschner et al., 1999; Chan et al., 2008). Thus, we quantified the degree of GFAP staining in the olfactory bulbs of Tg and WT animals to rule out confounding influence of astrogliosis in the Tg group. GFAP staining was comparable between WT and Tg animal at all ages, both in the external plexiform layer and in the mitral cell layer (Fig.6 A\&B, and supplementary Fig. 9 I-L).

Another potentially confounding variable to consider is a possible neuronal loss in the olfactory system of the tauopathy animals. To investigate this, we performed a semiquantitative evaluation of neuronal density in the olfactory system of Tg and WT animals, by visual ranking. No significant difference was observed between $\mathrm{Tg}$ and WT in neuronal density within the glomerular layer, the mitral cell layer and the anterior piriform cortex at 3 and 6 month-old (data not shown). To definitely rule out neuronal loss in Tg animals, we performed an unbiased stereological quantification of neurons in the mitral cell layer of all animals. The average number of neurons per $\mathrm{mm}^{3}$ did not differ significantly between 3 and 6 month-old Tg mice, or between 6 month-old Tg mice and age-matched WT (Fig.6 C, and supplementary Fig. 9 M-P).

\subsection{Comparison of animals that underwent one single examination at 9 months of age, and those that were examined at 3, 6 and 9 months of age, suggests that the amount of administered manganese was not neurotoxic}

We did not observe significant difference in MEMRI parameters ( $\mathrm{Pv}, \mathrm{Pt}$ and $\mathrm{Sv}$ ) or in histological characteristics (MC1, PHF1 and GFAP staining, neuronal density) between the subgroup of 9 month-old animals which were examined only once, and the subgroup of 9 month-old animals that were examined repeatedly at 3,6 and 9 months of age, thus receiving three times more manganese (Fig.7).

\section{Discussion}

This in vivo study demonstrates an impairment of manganese propagation within the olfactory system of TgJNPL3 mice. Manganese propagation has been shown in the literature to be dependent on active axonal transport (Bearer et al., 2007a; Sloot and Gramsbergen, 1994; Smith et al., 2007; Takeda et al., 1998b). In pathological conditions, other phenomenon such as neuronal loss or gliosis could also impair neuronal transport, but we showed that these were absent in the TgJNPL3 mice we studied as compared to controls. Lastly, the significant correlations between manganese propagation parameters and levels of 
tauopathy in neurons assessed by immunohistochemistry strongly support the fact that manganese transport reflects active neuronal transport in our study. Thus, our results demonstrate for the first time an in vivo impairment of neuronal transport related to the expression of mutant human tau in JNPL3 mice. Our results are in agreement with previous studies obtained in other transgenic animal models of tauopathy, expressing R406W (Zhang et al., 2004) and K369I (Ittner et al., 2008) mutant human tau, in which invasive techniques were used to quantify axonal transport in spinal cord and peripheral nerves. Significantly, our protocol provides a non-invasive estimation of neuronal transport in the mouse brain, thus being more relevant for the study of tauopathies. Using a long time-frame MEMRI protocol, we were able to acquire serial 3D data set with $150 \mu \mathrm{m}$ isotropic spatial resolution and estimate the entire curve profile of manganese transport. This enabled us to calculate retrospectively different parameters of transport (i.e. peak value, maximal slope and time-topeak) in any desired pixels within the olfactory tract in which manganese propagates. Although the physical meaning of each parameter remains to be studied further, these measurements are very useful. The peak value gave the highest statistical significance for the comparison of WT and Tg animals (Fig. 2C \& 3C), whereas the maximal slope was the best parameter to monitor Tg mice during aging (Fig 2D \& 3D). These differences highlight the advantages afforded by the acquisition of the long time-frame protocol we used, which gives access to all parameters of manganese transport (Cross et al., 2008). In contrast, short time-frame protocols are more widely used in mice, less time-consuming, and do not require any image registration; but they are limited to the analysis of an anatomical region predefined experimentally using a single parameter, the slope of manganese progression (Kim et al., 2011; Massaad et al.; Smith et al., 2007; Smith et al., 2010a). Moreover, during short-time frame protocols, neuronal transport is studied during the acquisition of MR images, i.e. when the mouse is still and anesthetized. In contrast, long time-frame protocols spanning over multiple sessions enable the overall displacement of manganese to occur inbetween MR acquisitions while mice are fully awake and active within their usual environment; hence this allows the characterization of manganese transport under near physiological conditions.

In this study, we were able for the first time to correlate MEMRI parameters of neuronal transport (i.e. peak value and maximal slope) with a histological hallmark of a neurological disease, namely tau aggregates in neurons. Thus, our non invasive, in vivo and 4D approach provides a set of functional biomarkers of taupathy in transgenic mice. Predictably, this correlation was stronger when looking at the degree of pathological tau in the dendrites of neurons, than in the soma of neurons, as neuronal transport occurs mainly in dendrites and axons. PHF1 staining did not correlate as well as MC1 staining with the MEMRI measurements, which is likely related to PHF1 reactivity in normal tissue.

The strong correlation we obtained between MEMRI parameters and tau pathology in the dendritic compartment stresses the importance of transport alterations occurring in dendrites, which has not been investigated so far in tauopathies, as all studies have focused on the axonal compartment of neurons. Indeed, the dendritic compartment is challenging to explore even with videomicroscopy, because of the extreme tortuosity of dendritic branches as compared to the linearity of axons. Thus, MEMRI provides a unique tool for the exploration of neuronal transport at a global level, occurring from dendrites to axons.

The MEMRI technique we describe could be very useful for preclinical evaluation of new therapies against AD and related tauopathies: MEMRI could assess the functional benefit of therapeutic strategies for clearing pathological tau and/or for restoring a normal neuronal function. In this regard, the set of preclinical functional biomarkers we have described may be very useful for selecting efficient drugs against various neurodegenerative diseases such as tauopathies. 


\section{Supplementary Material}

Refer to Web version on PubMed Central for supplementary material.

\section{Acknowledgments}

We are thankful to Daniel H Turnbull and his group for the generous access to their lab. Peter Davies generously provided MC1 and PHF1 antibodies. We thank Mike Hutton and Jada Lewis for making their model available through Taconic.

Funding: This work was supported by: the National Institute of Health [AG 020197, AG 032611, E.M.S.]; the Alzheimer's Association [Zenith grant to E.M.S., IIRG-08-91618 to Y.Z.W.]; the American Health Assistance Foundation [A2008-155 to Y.Z.W]; the Tilker Medical Research Foundation and the NYU Applied Research Support Fund to Y.Z.W. A.B. is funded by the French Society of Radiology, the French Society of Neuroradiology, the French Ministry of Foreign Affairs and the Philippe Foundation.

\section{References}

Aschner M, Vrana KE, Zheng W. Manganese uptake and distribution in the central nervous system (CNS). Neurotoxicology. 1999; 20:173-180. [PubMed: 10385881]

Asuni AA, Boutajangout A, Quartermain D, Sigurdsson EM. Immunotherapy targeting pathological tau conformers in a tangle mouse model reduces brain pathology with associated functional improvements. J Neurosci. 2007; 27:9115-9129. [PubMed: 17715348]

Bearer EL, Falzone TL, Zhang X, Biris O, Rasin A, Jacobs RE. Role of neuronal activity and kinesin on tract tracing by manganese-enhanced MRI (MEMRI). Neuroimage. 2007a; 37(Suppl 1):S37-46. [PubMed: 17600729]

Bearer EL, Zhang X, Jacobs RE. Live imaging of neuronal connections by magnetic resonance: Robust transport in the hippocampal-septal memory circuit in a mouse model of Down syndrome. Neuroimage. 2007b; 37:230-242. [PubMed: 17566763]

Bramblett GT, Goedert M, Jakes R, Merrick SE, Trojanowski JQ, Lee VM. Abnormal tau phosphorylation at Ser396 in Alzheimer's disease recapitulates development and contributes to reduced microtubule binding. Neuron. 1993; 10:1089-1099. [PubMed: 8318230]

Chan KC, Cai KX, Su HX, Hung VK, Cheung MM, Chiu CT, Guo H, Jian Y, Chung SK, Wu WT, Wu EX. Early detection of neurodegeneration in brain ischemia by manganese-enhanced MRI. Conf Proc IEEE Eng Med Biol Soc. 2008; 2008:3884-3887. [PubMed: 19163561]

Cowan CM, Bossing T, Page A, Shepherd D, Mudher A. Soluble hyperphosphorylated tau causes microtubule breakdown and functionally compromises normal tau in vivo. Acta Neuropathol. 2010

Cross DJ, Flexman JA, Anzai Y, Maravilla KR, Minoshima S. Age-related decrease in axonal transport measured by MR imaging in vivo. Neuroimage. 2008; 39:915-926. [PubMed: 17980625]

Dayanandan R, Van Slegtenhorst M, Mack TG, Ko L, Yen SH, Leroy K, Brion JP, Anderton BH, Hutton $\mathrm{M}$, Lovestone $\mathrm{S}$. Mutations in tau reduce its microtubule binding properties in intact cells and affect its phosphorylation. FEBS Lett. 1999; 446:228-232. [PubMed: 10100846]

Dixit R, Ross JL, Goldman YE, Holzbaur EL. Differential regulation of dynein and kinesin motor proteins by tau. Science. 2008; 319:1086-1089. [PubMed: 18202255]

Drapeau P, Nachshen DA. Manganese fluxes and manganese-dependent neurotransmitter release in presynaptic nerve endings isolated from rat brain. J Physiol. 1984; 348:493-510. [PubMed: 6325673]

Drechsel DN, Hyman AA, Cobb MH, Kirschner MW. Modulation of the dynamic instability of tubulin assembly by the microtubule-associated protein tau. Mol Biol Cell. 1992; 3:1141-1154. [PubMed: 1421571]

Ebneth A, Godemann R, Stamer K, Illenberger S, Trinczek B, Mandelkow E. Overexpression of tau protein inhibits kinesin-dependent trafficking of vesicles, mitochondria, and endoplasmic reticulum: implications for Alzheimer's disease. J Cell Biol. 1998; 143:777-794. [PubMed: 9813097]

Eng LF, Ghirnikar RS, Lee YL. Glial fibrillary acidic protein: GFAP-thirty-one years (1969-2000). Neurochem Res. 2000; 25:1439-1451. [PubMed: 11059815] 
Falzone TL, Gunawardena S, McCleary D, Reis GF, Goldstein LS. Kinesin-1 transport reductions enhance human tau hyperphosphorylation, aggregation and neurodegeneration in animal models of tauopathies. Hum Mol Genet. 2010

Falzone TL, Stokin GB, Lillo C, Rodrigues EM, Westerman EL, Williams DS, Goldstein LS. Axonal stress kinase activation and tau misbehavior induced by kinesin- 1 transport defects. J Neurosci. 2009; 29:5758-5767. [PubMed: 19420244]

Grundke-Iqbal I, Iqbal K, Tung YC, Quinlan M, Wisniewski HM, Binder LI. Abnormal phosphorylation of the microtubule-associated protein tau (tau) in Alzheimer cytoskeletal pathology. Proc Natl Acad Sci U S A. 1986; 83:4913-4917. [PubMed: 3088567]

Iqbal K, Grundke-Iqbal I. Ubiquitination and abnormal phosphorylation of paired helical filaments in Alzheimer's disease. Mol Neurobiol. 1991; 5:399-410. [PubMed: 1726645]

Iqbal K, Grundke-Iqbal I, Zaidi T, Merz PA, Wen GY, Shaikh SS, Wisniewski HM, Alafuzoff I, Winblad B. Defective brain microtubule assembly in Alzheimer's disease. Lancet. 1986; 2:421426. [PubMed: 2874414]

Ishihara T, Hong M, Zhang B, Nakagawa Y, Lee MK, Trojanowski JQ, Lee VM. Age-dependent emergence and progression of a tauopathy in transgenic mice overexpressing the shortest human tau isoform. Neuron. 1999; 24:751-762. [PubMed: 10595524]

Ittner LM, Fath T, Ke YD, Bi M, van Eersel J, Li KM, Gunning P, Gotz J. Parkinsonism and impaired axonal transport in a mouse model of frontotemporal dementia. Proc Natl Acad Sci U S A. 2008; 105:15997-16002. [PubMed: 18832465]

Jicha GA, Berenfeld B, Davies P. Sequence requirements for formation of conformational variants of tau similar to those found in Alzheimer's disease. J Neurosci Res. 1999; 55:713-723. [PubMed: 10220112]

Kim J, Choi IY, Michaelis ML, Lee P. Quantitative in vivo measurement of early axonal transport deficits in a triple transgenic mouse model of Alzheimer's disease using manganese-enhanced MRI. Neuroimage. 2011

LaPointe NE, Morfini G, Pigino G, Gaisina IN, Kozikowski AP, Binder LI, Brady ST. The amino terminus of tau inhibits kinesin-dependent axonal transport: implications for filament toxicity. J Neurosci Res. 2009; 87:440-451. [PubMed: 18798283]

Lee VM, Goedert M, Trojanowski JQ. Neurodegenerative tauopathies. Annu Rev Neurosci. 2001; 24:1121-1159. [PubMed: 11520930]

Lee VM, Trojanowski JQ. The disordered neuronal cytoskeleton in Alzheimer's disease. Curr Opin Neurobiol. 1992; 2:653-656. [PubMed: 1422122]

Lewis J, McGowan E, Rockwood J, Melrose H, Nacharaju P, Van Slegtenhorst M, Gwinn-Hardy K, Paul Murphy M, Baker M, Yu X, Duff K, Hardy J, Corral A, Lin WL, Yen SH, Dickson DW, Davies P, Hutton M. Neurofibrillary tangles, amyotrophy and progressive motor disturbance in mice expressing mutant (P301L) tau protein. Nat Genet. 2000; 25:402-405. [PubMed: 10932182]

Lin YJ, Koretsky AP. Manganese ion enhances T1-weighted MRI during brain activation: an approach to direct imaging of brain function. Magn Reson Med. 1997; 38:378-388. [PubMed: 9339438]

Lovestone S, Hartley CL, Pearce J, Anderton BH. Phosphorylation of tau by glycogen synthase kinase- 3 beta in intact mammalian cells: the effects on the organization and stability of microtubules. Neuroscience. 1996; 73:1145-1157. [PubMed: 8809831]

Lu H, Xi ZX, Gitajn L, Rea W, Yang Y, Stein EA. Cocaine-induced brain activation detected by dynamic manganese-enhanced magnetic resonance imaging (MEMRI). Proc Natl Acad Sci U S A. 2007; 104:2489-2494. [PubMed: 17287361]

Mandelkow EM, Stamer K, Vogel R, Thies E, Mandelkow E. Clogging of axons by tau, inhibition of axonal traffic and starvation of synapses. Neurobiol Aging. 2003; 24:1079-1085. [PubMed: 14643379]

Massaad CA, Amin SK, Hu L, Mei Y, Klann E, Pautler RG. Mitochondrial superoxide contributes to blood flow and axonal transport deficits in the Tg2576 mouse model of Alzheimer's disease. PLoS One. 2010; 5:e10561. [PubMed: 20479943]

Matsuda K, Wang HX, Suo C, McCombe D, Horne MK, Morrison WA, Egan GF. Retrograde axonal tracing using manganese enhanced magnetic resonance imaging. Neuroimage. 2010; 50:366-374. [PubMed: 20074651] 
Mudher A, Shepherd D, Newman TA, Mildren P, Jukes JP, Squire A, Mears A, Drummond JA, Berg S, MacKay D, Asuni AA, Bhat R, Lovestone S. GSK-3beta inhibition reverses axonal transport defects and behavioural phenotypes in Drosophila. Mol Psychiatry. 2004; 9:522-530. [PubMed: 14993907]

Narita K, Kawasaki F, Kita H. Mn and Mg influxes through Ca channels of motor nerve terminals are prevented by verapamil in frogs. Brain Res. 1990; 510:289-295. [PubMed: 2158851]

Neelavalli J, Haacke EM. A simplified formula for T1 contrast optimization for short-TR steady-state incoherent (spoiled) gradient echo sequences. Magn Reson Imaging. 2007; 25:1397-1401. [PubMed: 17509786]

Otvos L Jr, Feiner L, Lang E, Szendrei GI, Goedert M, Lee VM. Monoclonal antibody PHF-1 recognizes tau protein phosphorylated at serine residues 396 and 404. J Neurosci Res. 1994; 39:669-673. [PubMed: 7534834]

Pautler RG, Koretsky AP. Tracing odor-induced activation in the olfactory bulbs of mice using manganese-enhanced magnetic resonance imaging. Neuroimage. 2002; 16:441-448. [PubMed: 12030829]

Pautler RG, Silva AC, Koretsky AP. In vivo neuronal tract tracing using manganese-enhanced magnetic resonance imaging. Magn Reson Med. 1998; 40:740-748. [PubMed: 9797158]

Saleem KS, Pauls JM, Augath M, Trinath T, Prause BA, Hashikawa T, Logothetis NK. Magnetic resonance imaging of neuronal connections in the macaque monkey. Neuron. 2002; 34:685-700. [PubMed: 12062017]

Seitz A, Kojima H, Oiwa K, Mandelkow EM, Song YH, Mandelkow E. Single-molecule investigation of the interference between kinesin, tau and MAP2c. EMBO J. 2002; 21:4896-4905. [PubMed: 12234929]

Sigurdsson EM. Histological staining of amyloid-beta in mouse brains. Methods Mol Biol. 2005; 299:299-308. [PubMed: 15980613]

Sloot WN, Gramsbergen JB. Axonal transport of manganese and its relevance to selective neurotoxicity in the rat basal ganglia. Brain Res. 1994; 657:124-132. [PubMed: 7820609]

Smith KD, Kallhoff V, Zheng H, Pautler RG. In vivo axonal transport rates decrease in a mouse model of Alzheimer's disease. Neuroimage. 2007; 35:1401-1408. [PubMed: 17369054]

Smith KD, Paylor R, Pautler RG. R-flurbiprofen improves axonal transport in the Tg2576 mouse model of Alzheimer's disease as determined by MEMRI. Magn Reson Med. 2010a; 65:14231429. [PubMed: 21500269]

Smith KD, Peethumnongsin E, Lin H, Zheng H, Pautler RG. Increased Human Wildtype Tau Attenuates Axonal Transport Deficits Caused by Loss of APP in Mouse Models. Magn Reson Insights. 2010b; 4:11-18. [PubMed: 20798780]

Stokin GB, Lillo C, Falzone TL, Brusch RG, Rockenstein E, Mount SL, Raman R, Davies P, Masliah E, Williams DS, Goldstein LS. Axonopathy and transport deficits early in the pathogenesis of Alzheimer's disease. Science. 2005; 307:1282-1288. [PubMed: 15731448]

Stoothoff W, Jones PB, Spires-Jones TL, Joyner D, Chhabra E, Bercury K, Fan Z, Xie H, Bacskai B, Edd J, Irimia D, Hyman BT. Differential effect of three-repeat and four-repeat tau on mitochondrial axonal transport. J Neurochem. 2009; 111:417-427. [PubMed: 19686388]

Takeda A, Ishiwatari S, Okada S. In vivo stimulation-induced release of manganese in rat amygdala. Brain Res. 1998a; 811:147-151. [PubMed: 9804933]

Takeda A, Kodama Y, Ishiwatari S, Okada S. Manganese transport in the neural circuit of rat CNS. Brain Research Bulletin. 1998b; 45:149-152. [PubMed: 9443831]

Tjalve H, Henriksson J, Tallkvist J, Larsson BS, Lindquist NG. Uptake of manganese and cadmium from the nasal mucosa into the central nervous system via olfactory pathways in rats. Pharmacol Toxicol. 1996; 79:347-356. [PubMed: 9000264]

Tjalve H, Mejare C, Borg-Neczak K. Uptake and transport of manganese in primary and secondary olfactory neurones in pike. Pharmacol Toxicol. 1995; 77:23-31. [PubMed: 8532608]

Trinczek B, Ebneth A, Mandelkow EM, Mandelkow E. Tau regulates the attachment/detachment but not the speed of motors in microtubule-dependent transport of single vesicles and organelles. $\mathrm{J}$ Cell Sci. 1999; 112(Pt 14):2355-2367. [PubMed: 10381391] 
Vershinin M, Carter BC, Razafsky DS, King SJ, Gross SP. Multiple-motor based transport and its regulation by Tau. Proc Natl Acad Sci U S A. 2007; 104:87-92. [PubMed: 17190808]

Vossel KA, Zhang K, Brodbeck J, Daub AC, Sharma P, Finkbeiner S, Cui B, Mucke L. Tau Reduction Prevents A $\{$ beta\}-Induced Defects in Axonal Transport. Science. 2010

Wood ML, Hardy PA. Proton relaxation enhancement. J Magn Reson Imaging. 1993; 3:149-156. [PubMed: 8428082]

Yuan A, Kumar A, Peterhoff C, Duff K, Nixon RA. Axonal transport rates in vivo are unaffected by tau deletion or overexpression in mice. J Neurosci. 2008; 28:1682-1687. [PubMed: 18272688]

Zhang B, Higuchi M, Yoshiyama Y, Ishihara T, Forman MS, Martinez D, Joyce S, Trojanowski JQ, Lee VM. Retarded axonal transport of R406W mutant tau in transgenic mice with a neurodegenerative tauopathy. J Neurosci. 2004; 24:4657-4667. [PubMed: 15140937]

Zhang B, Maiti A, Shively S, Lakhani F, McDonald-Jones G, Bruce J, Lee EB, Xie SX, Joyce S, Li C, Toleikis PM, Lee VM, Trojanowski JQ. Microtubule-binding drugs offset tau sequestration by stabilizing microtubules and reversing fast axonal transport deficits in a tauopathy model. Proc Natl Acad Sci U S A. 2005; 102:227-231. [PubMed: 15615853] 


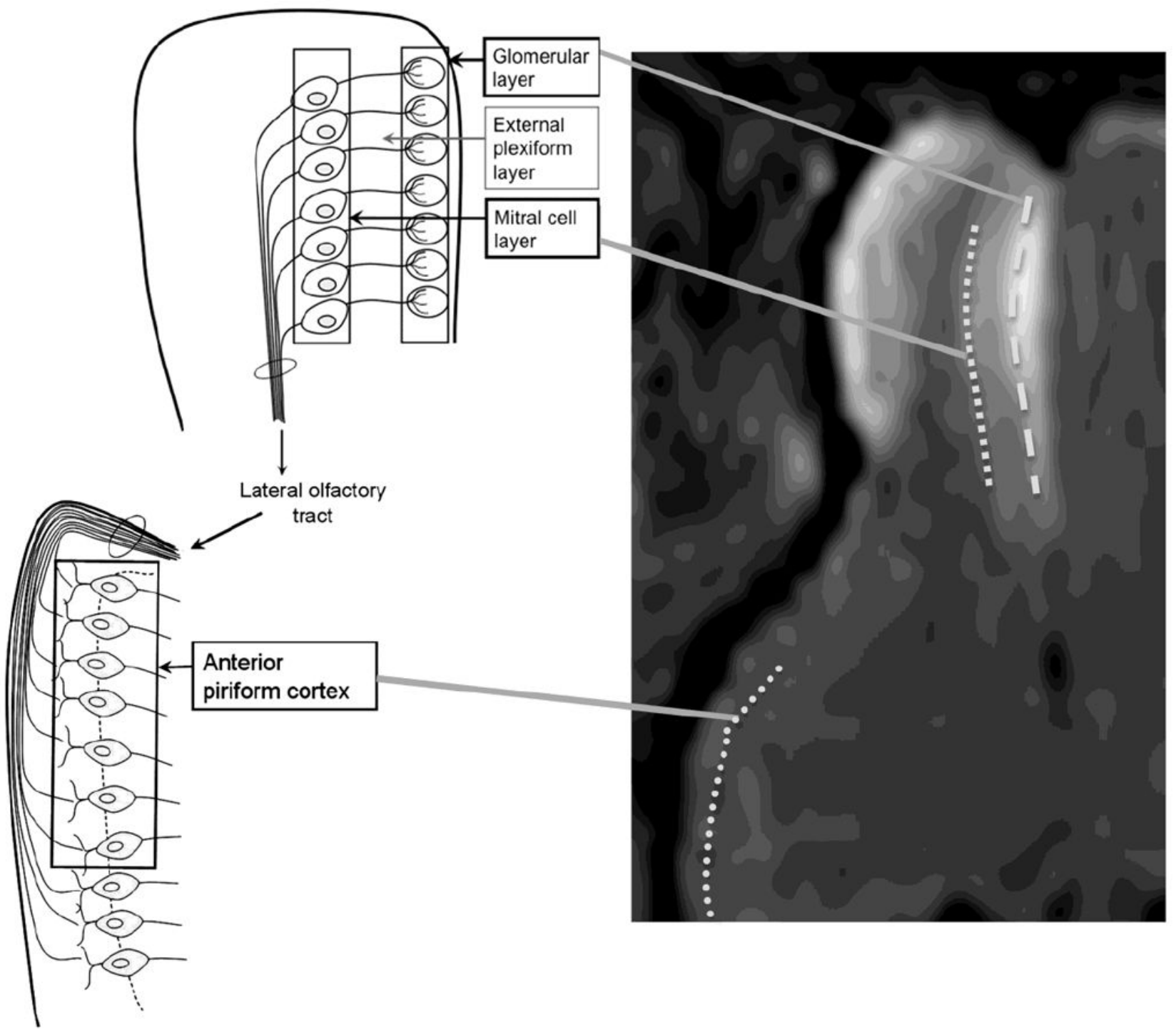

Fig.1.

Regions of interest. Diagrammatic representation (left side) of the regions of interest placed on MR images (right side, axial view of the mouse brain). On this T1-weighted sequence performed $8 \mathrm{~h}$ after nasal manganese injection, the areas of increased signal intensity (white color) correspond to the anatomical regions in which Mn propagates along the olfactory tract and accumulates transiently in high concentration (Pautler et al., 1998). The glomerular layer and the mitral cell layer both appear as hyperintensity separated by a narrow hypointense rim. 

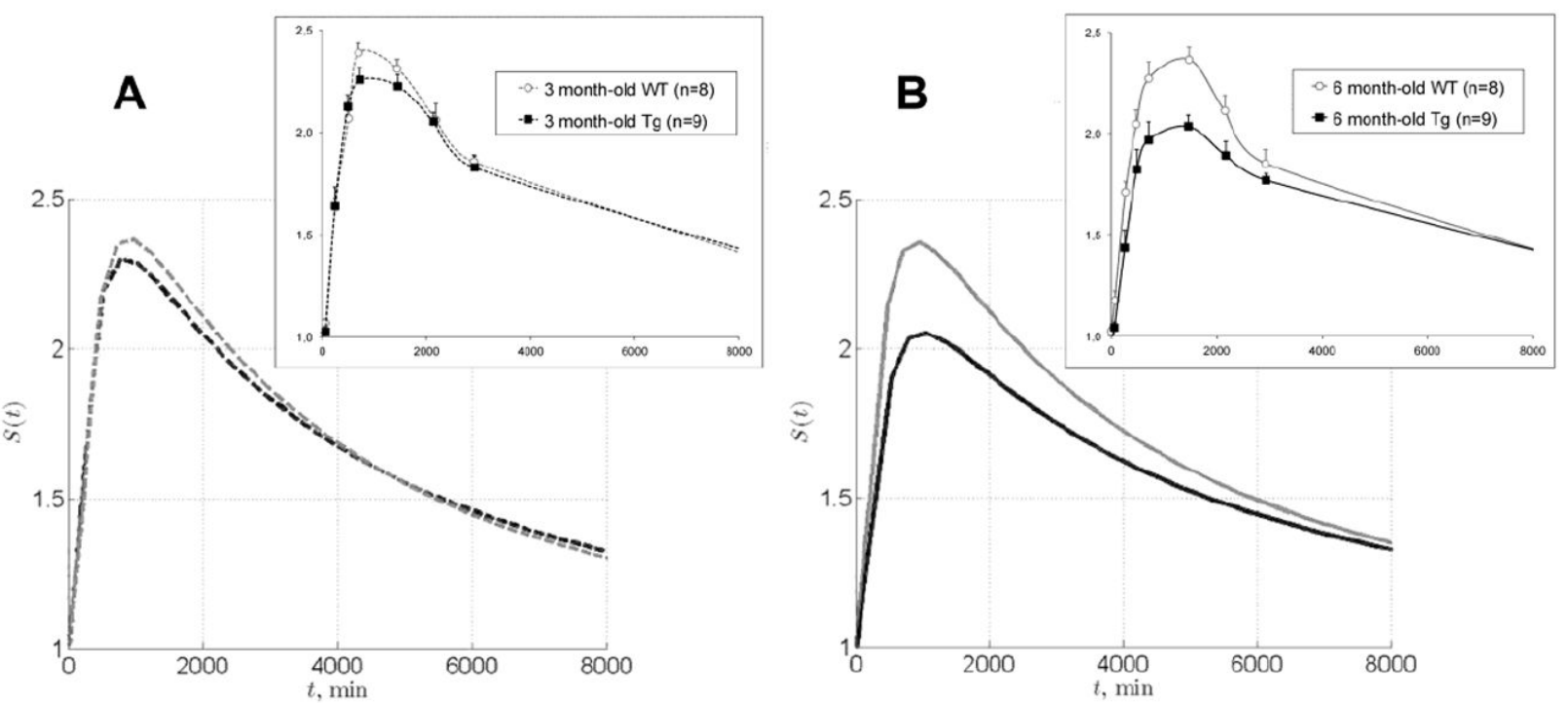

\section{Peak value in the glomerular layer}

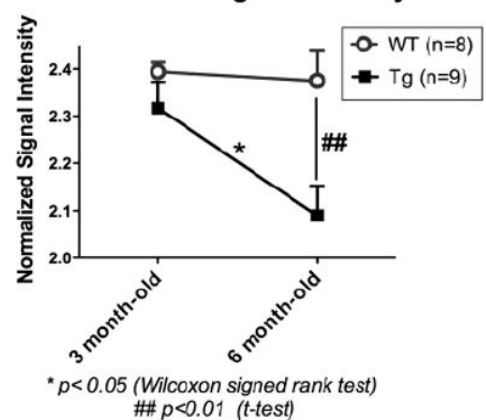

D. Maximal slope in the glomerular layer

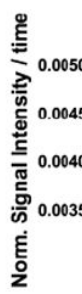

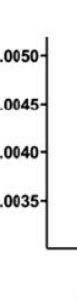

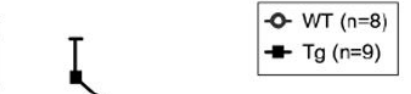

E. Time-to-peak in the glomerular layer

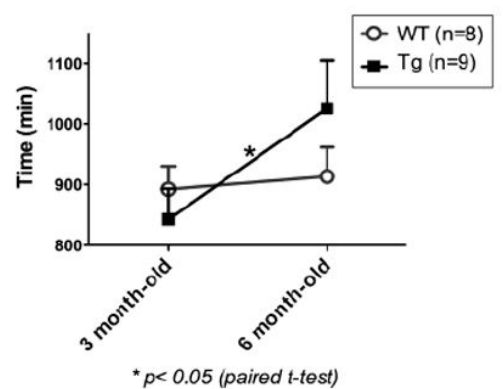

Fig. 2.

Curve profiles of Mn transport in the glomerular layer were similar between $\mathrm{Tg}$ and WT at 3 months of age (A), but showed marked differences at 6 months of age (B) (raw data are presented as inserts to depict the mean and standard deviation of all the subjects considered in the fit). The fitting process enabled the extraction of curve parameters (i.e., peak value, maximal slope and time-to peak) in each animal. Curve parameters of 6 month-old $\mathrm{Tg}$ animals were significantly different from those of same animals at 3 months of age $(\mathrm{C}$, D\&E), and from those of age-matched WT (C). Mean value is represented for each group, with the standard error of the mean. 

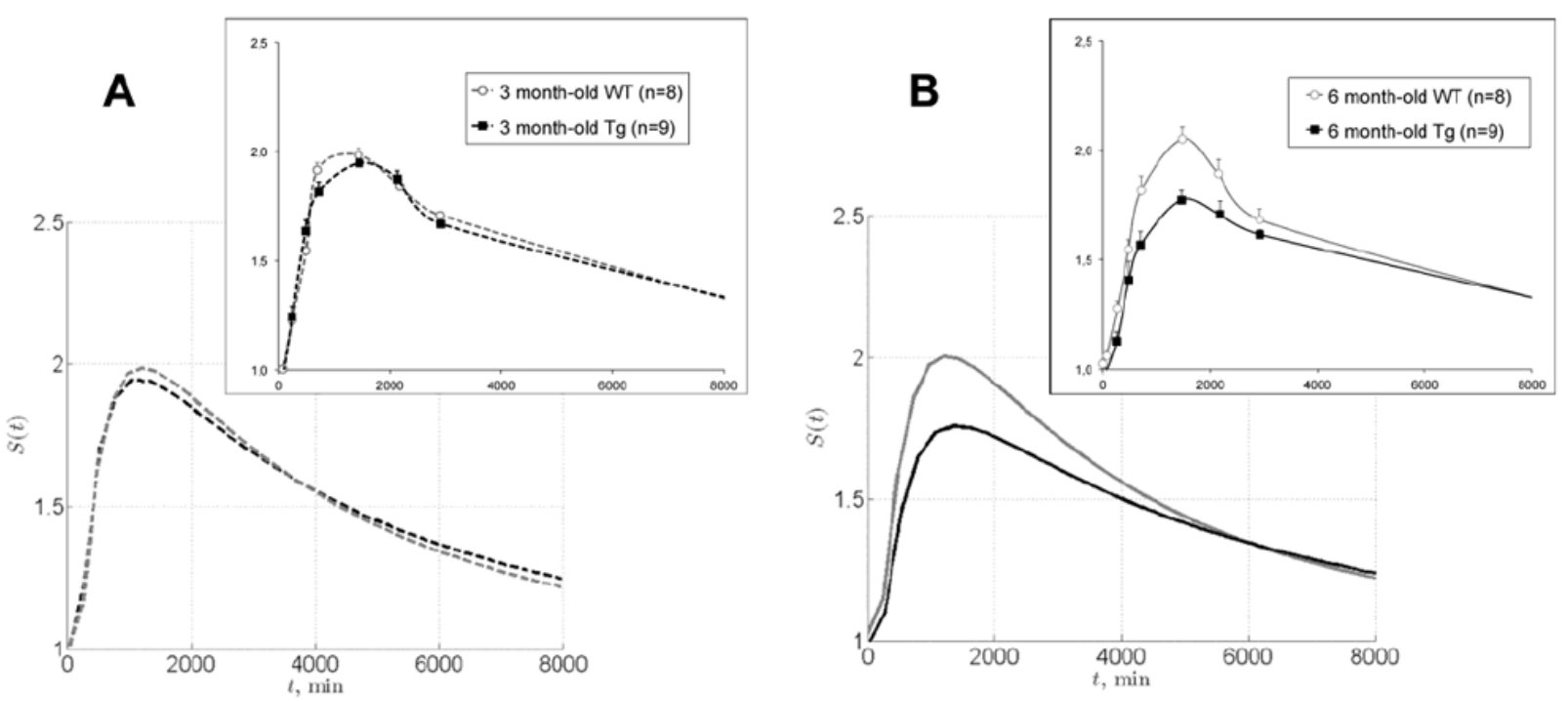

C. Peak value in the mitral cell layer

D. Maximal slope in the mitral cell layer

E. Time-to-peak in the mitral cell layer
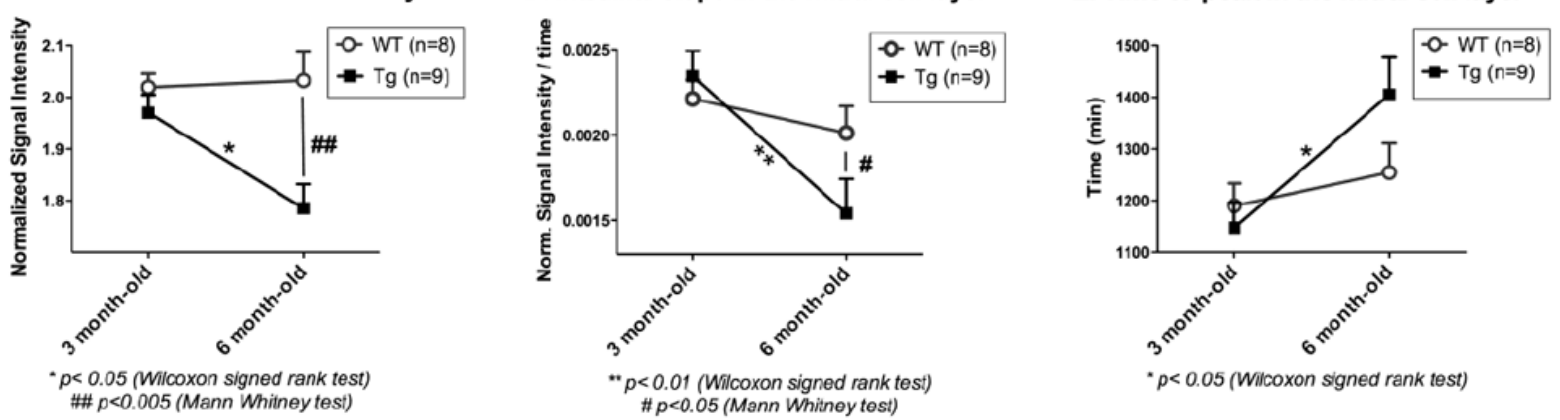

Fig. 3.

Curve profiles of Mn transport in the mitral cell layer were similar between Tg and WT at 3 months of age (A), but showed marked differences at 6 months of age (B) (raw data are presented as inserts including the mean and standard deviation of all the subjects considered in the fit). Curve parameters of 6 month-old $\mathrm{Tg}$ animals were significantly different from those of same animals at 3 months of age (C, D\&E), and from those of age-matched WT (C\&D). Mean value is represented for each group, with the standard error of the mean. 


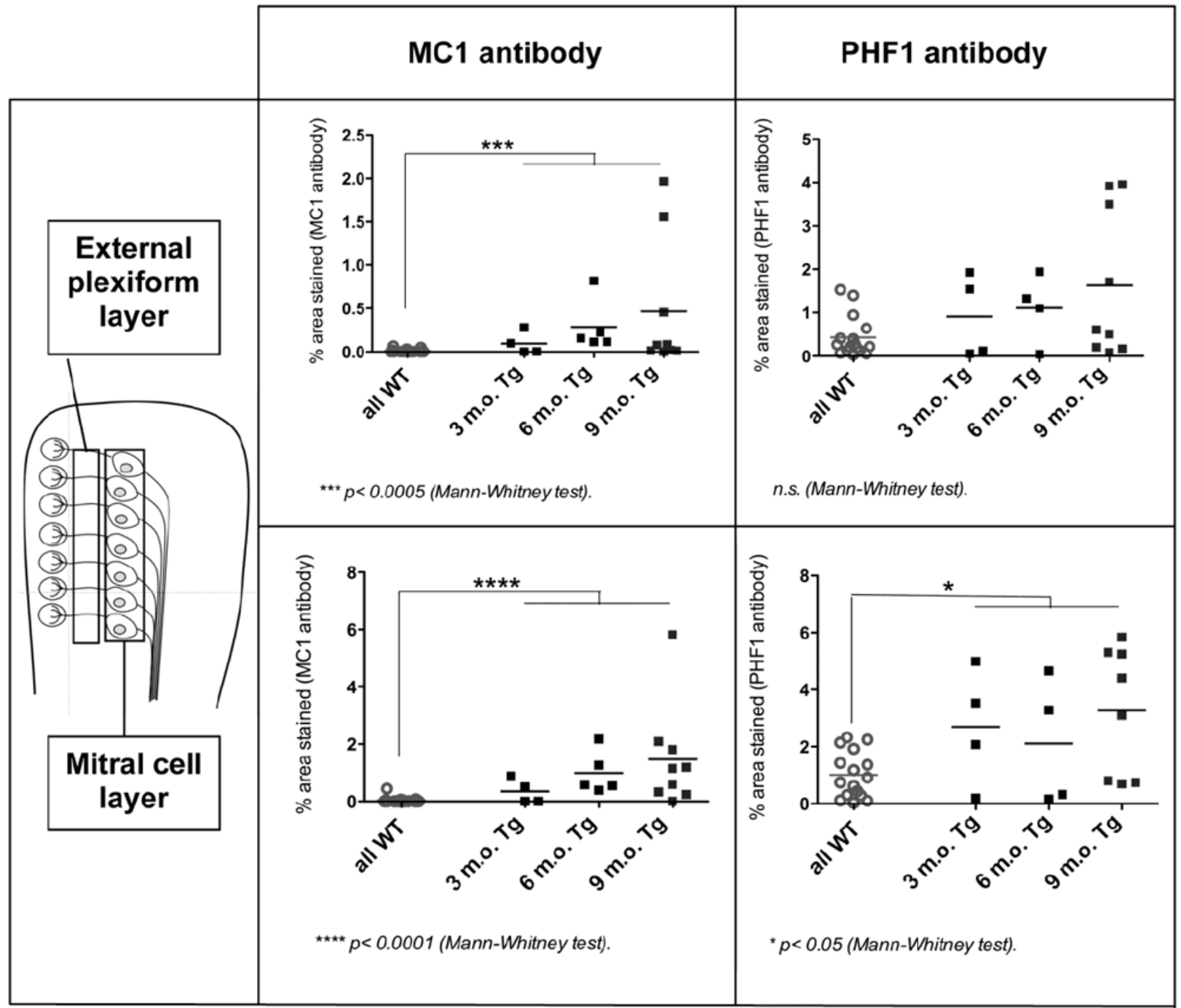

Fig.4.

Progression of tau pathology over time in the different regions of interest, evaluated by immunohistochemistry (MC1 and PHF1 antibodies). Statistically significant differences are observed when comparing tau pathology between the whole WT group and the whole Tg group. A trend of increased pathology with age is observed in Tg animals; this trend does not reach statistical significance because of the high inter-subject variability of pathology expression which exists in this strain. (m.o. = month-old). 


\section{Tau pathology in cell bodies}

A. Peak value correlates with somatic tau pathology (PHF1 antibody)

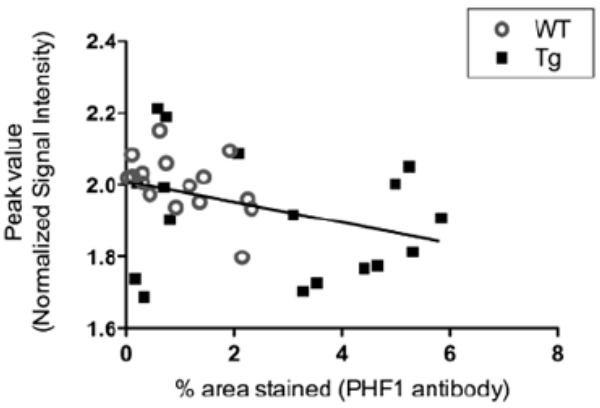

Correlation : $r=-0.38$ and $p<0.05$ (Spearman correlation coefficient).
B. Peak value correlates with somatic tau pathology (MC1 antibody)

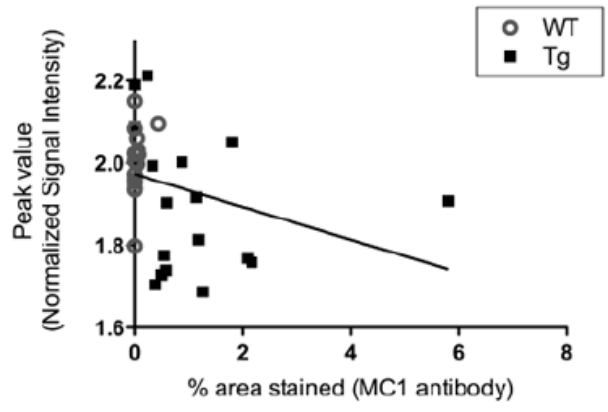

Correlation: $r=-0.46$ and $p<0.01$ (Spearman correlation coefficient).

\section{Tau pathology in dendrites}

C. Peak value correlates with dendritic tau pathology (PHF1 antibody)

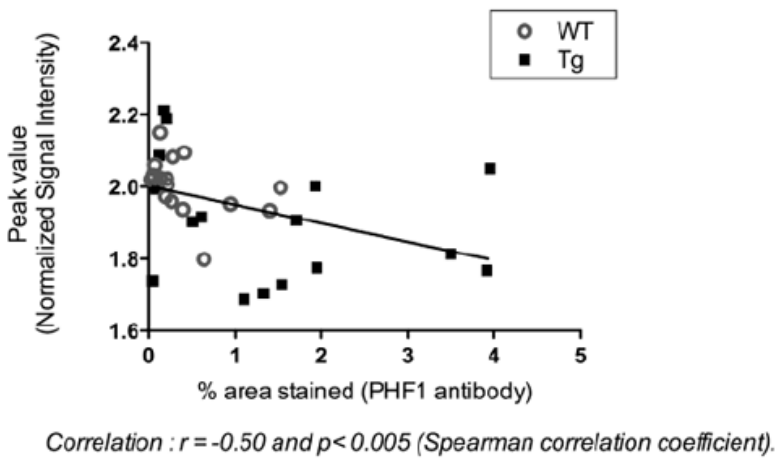

D. Peak value correlates with dendritic tau pathology (MC1 antibody)

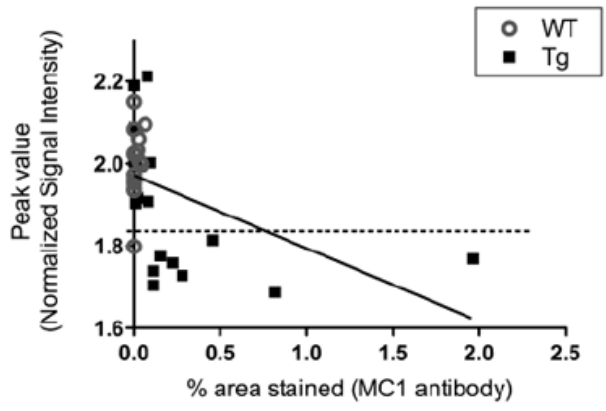

Correlation: $r=-0.50$ and $p<0.005$ (Spearman correlation coefficient).

Fig. 5.

Peak value measured in the mitral cell layer correlated significantly with tau pathology (MC1 and PHF1 antibodies). Statistical significance was higher when considering dendritic tau $(C \& D)$ than somatic tau (A\&B). A threshold of 1.85 for the peak value allowed the separation of all $\mathrm{Tg}$ animals with MC1-positive dendrites (stained area $>0.5 \%$ ), from all $\mathrm{Tg}$ animals with low levels of MC1 dendritic staining (stained area $<0.1 \%$ ) and all except one WT animal (Fig 5D). 


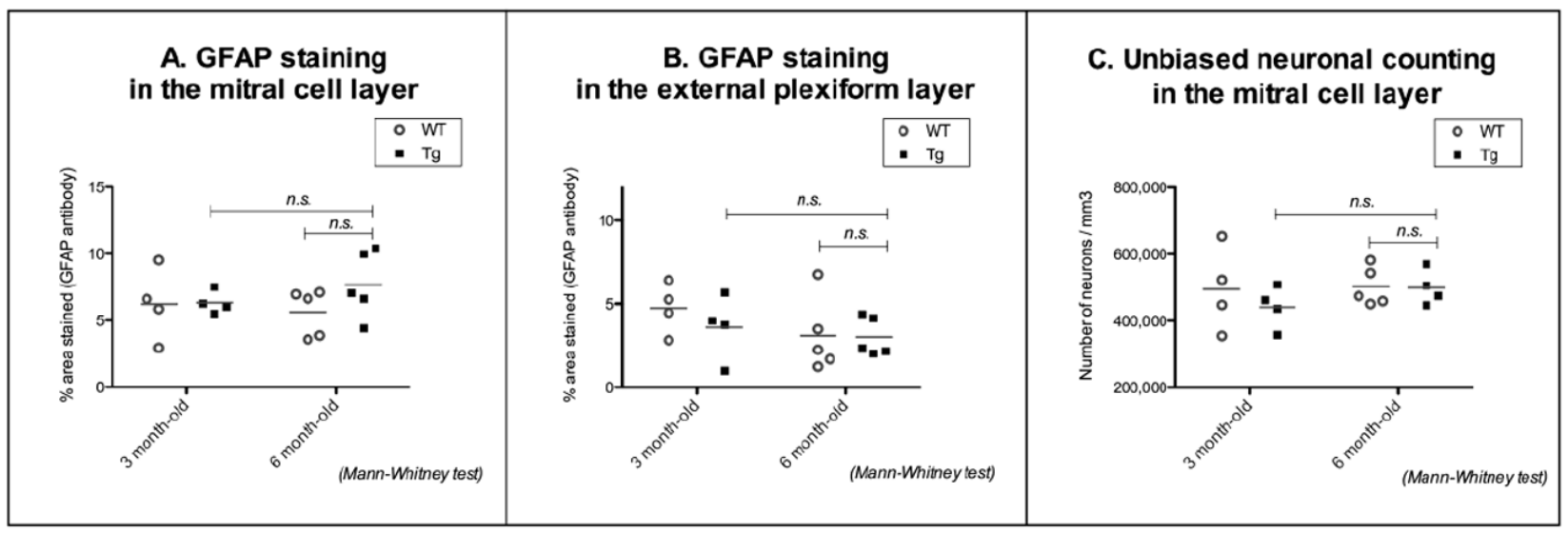

Fig. 6.

Levels of GFAP staining (A\&B) did not differ significantly between WT and Tg animals at all ages, ruling out the occurrence of astrogliosis in the Tg group. Unbiased cell counting in the mitral cell layer (C) did not show any significant neuronal loss in the Tg group as compared with WT. 


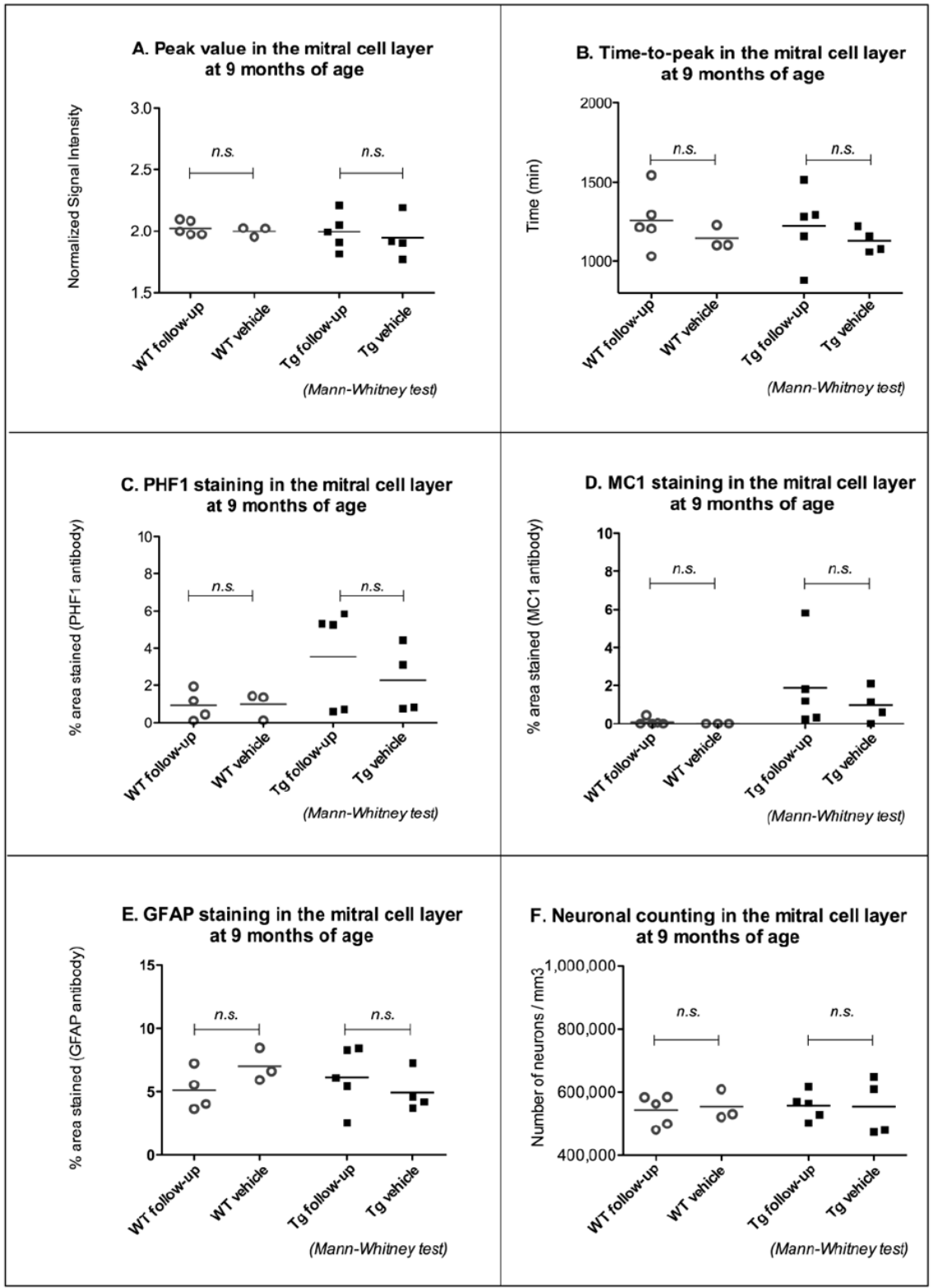

Fig. 7.

Comparison of MEMRI parameters (A\&B) and histological characteristics (C-F) at 9 months of age, between the follow-up subgroup (mice injected and examined at 3,6 and 9 months of age) and the vehicle subgroup (mice injected and examined at 9 months of age only). No statistical difference was observed between the two subgroups for any of the parameters. 